\title{
Study of the effect of sodium alginate coating containing pomegranate peel extract on chemical, sensory and microbial quality of walnut kernel
}

\author{
Fatemeh Davoodi $^{\circledR}{ }^{\circledR}$, Mohammad Hadi Naji ${ }^{*}{ }^{*}$ \\ ${ }^{1}$ Department of Food Science \& Technology, Yasooj Branch, Islamic Azad University, Yasooj , Iran \\ ${ }^{2}$ Department of Food Science \& Technology, Zarin Dasht Branch, Islamic Azad University, Zarin Dasht, Iran
}

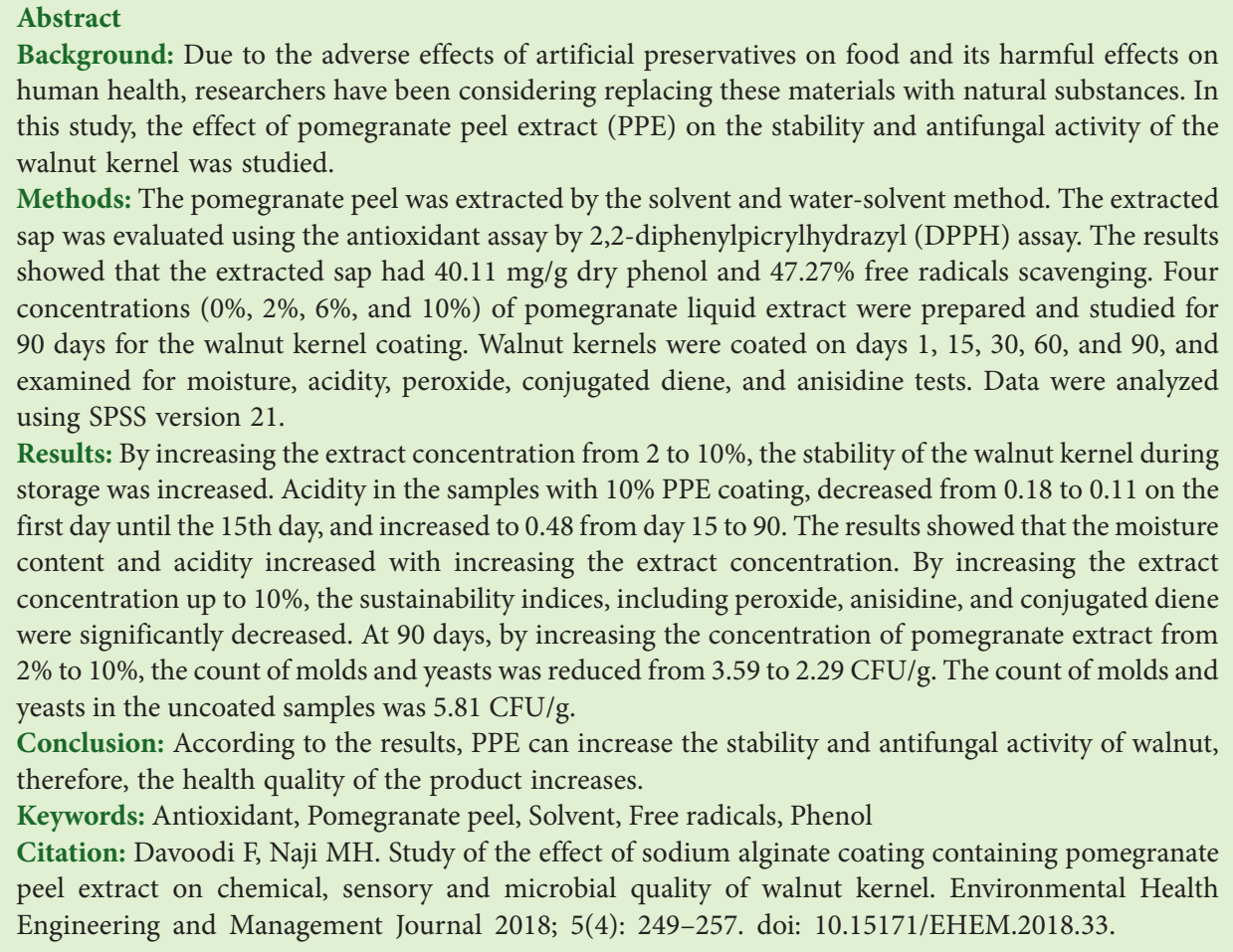

Article History:

Received: 25 September 2018 Accepted: 11 November 2018 ePublished: 21 November 2018

\section{Introduction}

Food safety refers to the conditions and practices that are considered during the production, processing, storage, and distribution of food to ensure that food is safe for consumption. Consumption of contaminated food can result in bloody diarrhea and vomiting, abdominal cramping, fever, headache, etc $(1,2)$. Walnut is a product that is highly perishable under natural storage conditions (3). High levels of fat (65\%) and unsaturated fatty acids in the walnut make them susceptible to severe oxidative rancidity. Oxidation reactions occur in the presence of internal factors such as the natural oxidizing enzymes present in the walnut (e.g., lipoxygenase). Enzyme activation is a long process. However, the availability of conditions can exacerbate it. In fact, the walnut's oxidation capacity is influenced by factors such as oxygen concentration, temperature, relative humidity, light, antioxidants, and processing methods $(4,5)$. The harmful effects of fat oxidation in foods are delayed using antioxidants and natural preservatives. Additionally, fat oxidation effectively reduces oxygen permeation by choosing edible films and coating (6). The use of edible films helps maintain product quality, improves product safety, and increases the shelf life of all types of ready-toeat food (7). The use of edible films and coatings has been proposed as a carrier of antioxidant and antimicrobial agents for food packaging (8). The use of films and coatings due to the properties such as inhibition of 
moisture evaporation, oxygen permeation, preservation of taste, smell and color for food, increases the quality and shelf life of them. Sodium alginate is an emulsifier, stabilizer, and condenser. This film is completely watersoluble, glossy that preserves the aroma, taste, and color, increases the nutritional value of the product, such as vitamins and essential amino acids, prevents the activity of enzymes, and reduces the amount of waste. The high ability of alginates to form films makes it possible to use it as an appropriate food cover. Obviously, the presence of antibacterial and antioxidant compounds increasing its storage properties. Pomegranate peel is a waste material and one of the products of the juice production plants. Pomegranate peel is known as a rich source of polyphenols (9). Coatings are films that are used directly on the surface of the foodstuff. Therefore, coatings are considered as a part of the final product (8). Phenolic compounds present in pomegranate skin exhibit high antibacterial properties (10). There are reports of phenolic compounds, especially punicalagin obtained from pomegranate skin, which shows its antimicrobial properties against Candida albicans (11). Antifungal property of pomegranate peel extract (PPE) has been reported according to the type of tested microorganisms. In China, even in some cases, PPE is used to produce fungicides (12). The inhibitory effects of pomegranate peel on microorganisms have been proven in some studies (13-15). However, its antifungal effect on the walnut has not been investigated. Recently, antioxidants and natural preservatives in the food industry have become more favored than synthetic antioxidants. In the meantime, pomegranate and its derivatives have been shown to delay the process of fat oxidation in vitro and in vivo experiments (16-18). Reports have shown that pomegranate skin is a rich source of tannin, phenols, and flavonoids that have significant antioxidant activity (1921). Yazdanpanah et al investigated the thermal stability of antioxidant extracts of pomegranate skin on sunflower oil. In this research, anti-oxidant compounds of pomegranate skin were extracted by two ethanol and methanol solvents using percolation method and their antioxidant activity was determined by phosphomolybdenum method. It was found that methanolic extract has higher antioxidant activity than ethanolic one. In the next step, the thermal stability of methanolic extract was evaluated by the Rancimat method at temperatures of 90,120 , and $150^{\circ} \mathrm{C}$, compared with a-tocopherol and BHT. Finally, it was found that the induction period of the sample containing $1000 \mathrm{ppm}$ of methanolic extract of pomegranate skin was significantly higher than the other samples at all three temperatures (22). Selahvarzi et al examined the mechanism of control of post-harvest fungi by extracting various parts of the pomegranate. The results showed that the inhibitory effect of pomegranate methanolic extracts on the mycelia growth and fungal spore germination was $47.6 \%$ and $37.7 \%$, respectively. Also, the phenolic content of pomegranate peel was 1.8 times higher than that of leaf, and antioxidant capacity of pomegranate peel, seeds and leaves was $55.3 \%, 35.7 \%$, and $16.4 \%$, respectively. Therefore, phenolic content of the pomegranate peel and seeds seem to have antifungal properties and potent antioxidant capacity of these extracts (23). The purpose of this study was to evaluate the effect of PPE on the fungal activity, the quality and durability of the walnut kernel during storage.

\section{Materials and Methods}

Pomegranate peel was collected from gardens of Fars province and dried at ambient temperature, ground to make powder, and stored at $4^{\circ} \mathrm{C}$ until the test (24). The solvents and other chemicals (purity $>99 \%$ ) used in this study, were obtained from the Sigma Aldrich.

\section{Pomegranate peel extraction}

To prepare PPE, $20 \mathrm{~g}$ of pomegranate peel powder was mixed with water (1:5 ratio) and then, placed in the bainmarie shaker at $80^{\circ} \mathrm{C}$ for 10 minutes. Finally, the extract was filtered using the Whatman No. 1 paper filter and stored at $-18^{\circ} \mathrm{C}$ until the experiment time (25).

\section{Measurement of total phenol content}

The total amount of phenolic compounds of PPE was determined by Folin-Ciocalteu at $735 \mathrm{~nm}$ wavelength by a spectrophotometer (UV-Vis, Shimadzu UV-2600/2700 model). Total phenol content of PPE was expressed by applying a standard curve as milligrams of Gallic acid per gram of dry matter (26).

Evaluation of radical inhibitory strength (DPPH) The antioxidant activity of PPE was evaluated by the Burits and Bucar method (27). According to this method, $50 \mu \mathrm{L}$ of different concentrations of the extract in methanol was added to $5 \mathrm{~mL}$ of $0.004 \%$ solution of DPPH in methanol. After 30 minutes of incubation at room temperature, samples were read at $517 \mathrm{~nm}$ wavelength by the spectrophotometer. The percentage of inhibition of DPPH free radicals was calculated using equation (1).

$\mathrm{I} \%=($ A blank-A sample $/ \mathrm{A}$ blank $) \times 100$

Where A blank shows a negative control absorbance of the sample without extract, and A sample expresses the absorbance of various concentrations of the extract. Then, the concentration of the extract with a radical inhibitory concentration of 50 (IC 50) was calculated by the graph. Butylated hydroxyanisole (BHA) was used as a reference compound (27).

\section{Coating}

The walnut kernels (in certain quantities) were immersed in the solution of sodium alginate containing 2, 6, and $10 \%$ of the walnut kernel extract for 60 seconds. The coated walnut kernels with uncoated specimen were placed in an 
oven at $45^{\circ} \mathrm{C}$ for 3 hours, then placed in a polyethylene box and kept at room temperature for 90 days.

\section{Extraction of walnut kernel oil}

The walnut kernels were powered after peeling. The oil of walnut powder was extracted by Soxhlet extraction method using ethylene ether solvent at $45^{\circ} \mathrm{C}$. The solvent was separated from the mixture by the oven and the extracted oil content was determined (28).

\section{Moisture measurement}

The moisture content of the coated walnut kernels was measured based on the American Association of Cereal Chemists (AACC, No. A 14-44) methods by oven device (29).

\section{Acidity measurement}

Walnut oil acidity was determined based on the reference method of Association of Official Analytical Chemists (AOAC). The acid number was calculated in terms of oleic acid (30).

\section{Measuring peroxide number}

To measure the peroxide number, chloroform/methanol solvents (7:3 ratio) was used. Then, the peroxide number of the samples was calculated according to the iron chloride standard (III) and using the following equation:

$\mathrm{PV}=(\mathrm{As}-\mathrm{Ab}) \times \mathrm{M} / 55.84 \times \mathrm{W} \times 2$

Where $A s$ is sample absorption, $A b$, the absorbance of the control (blank), $M$, the standard curve slope, and $W$, the oil mass (g) (31).

\section{Conjugated diene value}

The conjugated diene value was determined by Fathi et al by a spectrophotometer in the ultraviolet absorption range at $234 \mathrm{~nm}$ wavelength using hexane as a solvent of walnut oil. The results were calculated by the following equation:

$\mathrm{CDV}=\mathrm{A} \times 600 \times 1000 / 29000$

Where $A$ is differential of the absorbance of the sample at $234 \mathrm{~nm}$ wavelength and the absorbance of the control. The number 600 is the sample dilution in hexane and 29000 is the constant factor (32).

\section{Measurement of anisidine value}

Anisidine value (AV) was determined at $350 \mathrm{~nm}$ wavelength according to the AOCS Official Method Cd 18-90 (33).

Total count of mold and yeast

To determine the total count of mold and yeast, $10 \mathrm{~g}$ of walnut kernels was powdered under sterile condition. Walnut kernel powder was dissolved with $90 \mathrm{~mL}$ sterilized sodium chloride solution $(0.85 \%)$ and completely mixed. For cultivation and counting of mold and walnut samples, yeast extract glucose chloramphenicol medium (YGC) was used. After preparing the culture medium, the instructions were written on the container. After reaching $45^{\circ} \mathrm{C}$, under the microbial hood, the culture medium was added to each plate of 10 to $15 \mathrm{~mL}$. Using a sampler, $0.1 \mathrm{~mL}$ of sodium chloride solution and walnut powder mixture were added to the solid culture medium and spread completely using a special glass rod at the media. After a few minutes, the plates were incubated at $25^{\circ} \mathrm{C}$. After 5 days, the number of molds and yeast were grown was presented as the logarithm of colony-forming units per gram (CFU/g).

\section{Statistics analysis}

All experiments were performed in a completely randomized design with three replications. To compare means of treatments, Duncan test was used by SPSS version 21 software.

\section{Results}

Determination of the phenolic compounds

The phenolic compounds have a good antioxidant activity and are often found in fruits and vegetables. The results indicate that phenolic compounds and antioxidant properties are available in pomegranate $(34,35)$. The amount of phenolic compounds of PPE was determined to be $40.11 \mathrm{mg} / \mathrm{g}$ dry matter (Table 1 ).

\section{Percentage of free radical inhibition}

According to the results, PPE had high levels of radical inhibition, but did not have the ability to synthesize BHA as an antioxidant. Therefore, the type and concentration of extracts and synthetic antioxidants had a significant effect on free radical inhibition (Table 1).

\section{Walnut moisture content}

Moisture content decreased with an increase in time. In samples with $10 \%$ PPE coating, from the first day to 90 th day, moisture content decreased from $4.14 \%$ to $2.45 \%$. On the other hand, by increasing the amount of PPE on the walnut, moisture content increased. So that after 90 days, by increasing PPE coating from 2 to $10 \%$, the moisture content increased from 1.35 to $2.45 \%$. The lowest moisture content was observed in the uncoated sample (1.14). The effect of storage time on the moisture content of walnut samples was significant $(P<0.05)$, so that after 90 days of

Table1. Total phenol and free radical inhibition of pomegranate peel extract

\begin{tabular}{lcc}
\hline Treatment & $\begin{array}{c}\text { Total Phenol } \\
\text { (mg/g) }\end{array}$ & $\begin{array}{c}\text { Free Radical Inhibition } \\
\text { (\%) }\end{array}$ \\
\hline Pomegranate peel extract & $40.11 \pm 0.24$ & $47.27 \pm 1.02^{\mathrm{b}}$ \\
BHA & - & $63.21 \pm 0.00^{\mathrm{a}}$ \\
\hline
\end{tabular}




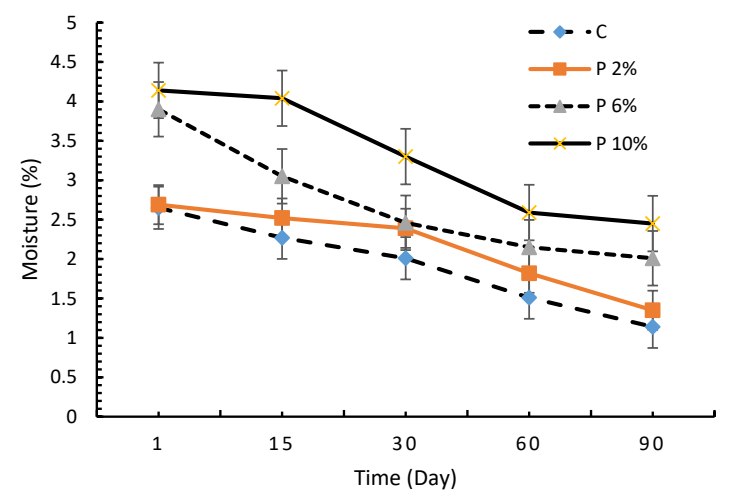

Figure 1. The effect of various concentrations of pomegranate peel extract coatings on the changes in the moisture content of walnut kernel during storage.

${ }^{*} \mathrm{C}$ : Uncoated samples, P $2 \%$ : Specimen with $2 \%$ pomegranate peel extract coating, P 6\%: Specimen with 6\% pomegranate peel extract coating, and $\mathrm{P}$ 10\%: Specimen with $10 \%$ pomegranate peel extract coating.

storage, the moisture content was significantly reduced. According to Figure 1, the uncoated samples had less moisture content.

Acidity

Acidity (in the coating of 10\%) decreased on the first day until 15th days, from 0.18 to 0.11 (\% oleic acid) and from day 15 to 90 , it increased to 0.48 (\% oleic acid). In the uncovered sample, the acidity in 0.199 (\% oleic acid) the first day was 0.199 and 0.84 ( $\%$ oleic acid )on 15th day decreased to 0.84 . From day 15 to day 90, acidity increased to 0.297 (\% oleic acid). The results of ANOVA showed that the effect of diverse concentrations of PPE on the acidity changes of the treated samples was significant $(P<0.05)$. According to Figure 2 , the effect of storage time was significant on the acidity of the walnut kernel samples $(P<0.05)$ and, after 90 days of storage, a significant increase in acidity was observed.

\section{Peroxide value}

The peroxide value (PV) increased with an increase in time. samples with 10\% PPE coating the PV increased from 0.42 to 22.47 milliequivalent ( $\mathrm{mEq}$ ) of oxygen per $\mathrm{kg}$ of oil from day 1 to 90 . By increasing percentage of PPE from 2 to $10 \%$ at 90 days, the PV decreased from 27.11 to $22.47 \mathrm{mEq}$. The uncoated samples had a PV of $33.38 \mathrm{mEq}$ of oxygen per kg of oil after 90 days. The results of ANOVA showed that the effect of various concentrations of PPE on the changes in PV was significant $(P<0.05)$. As shown in Figure 3, the effect of time on the PV of walnut kernels was significant $(P<0.05)$. After 90 days of storage, the PV increased significantly. In general, the results showed that increasing the concentration of the extract increased the stability of the product during storage.

Conjugated diene value

By increasing the concentration of PPE from $2 \%$ to $10 \%$

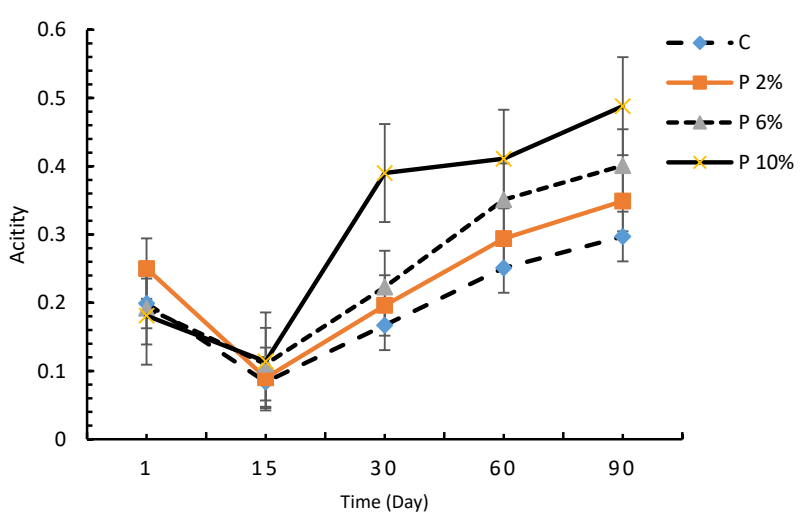

Figure 2. Effect of various concentrations of pomegranate peel extract on the changes in walnut kernel acidity during storage.

${ }^{*} \mathrm{C}$ : Uncoated samples, P $2 \%$ : Specimen with $2 \%$ pomegranate peel extract coating, P 6\%: Specimen with 6\% pomegranate peel extract coating, and P 10\%: Specimen with 10\% pomegranate peel extract coating.

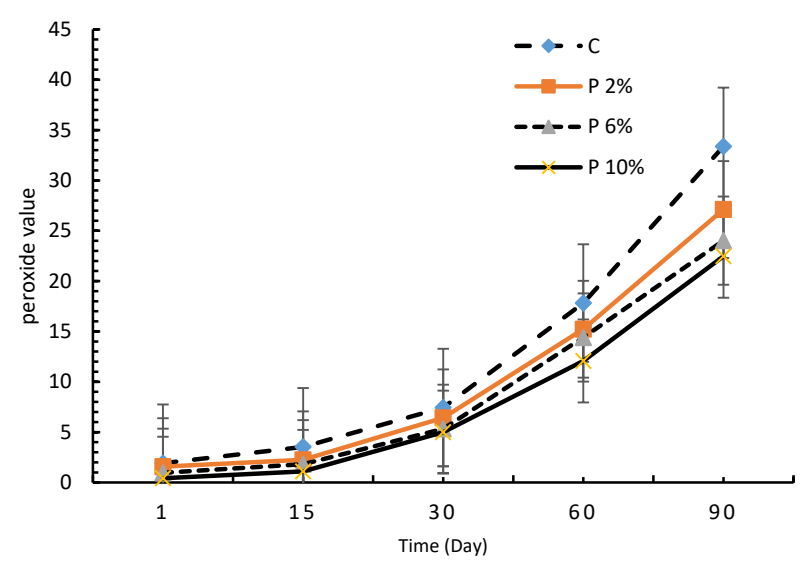

Figure 3. The effect of various concentrations of pomegranate peel extract on changes in walnut kernel peroxide value during storage. ${ }^{*} \mathrm{C}$ : Uncoated samples, P $2 \%$ : Specimen with $2 \%$ pomegranate peel extract coating, P 6\%: Specimen with 6\% pomegranate peel extract coating, and P 10\%: Specimen with 10\% pomegranate peel extract coating

in 90 days, conjugated diene value decreased from 24.45 to $19.34 \mathrm{mmol} / \mathrm{L}$. In the uncoated samples, the highest conjugated diene value was $27.02 \mathrm{mmol} / \mathrm{L}$. The results of ANOVA showed that the effect of various concentrations of PPE on the changes in the conjugated diene value of the treated samples was significant $(P<0.05)$. On the other hand, Figure 4 showed that the effect of storage time on the conjugated diene value in walnut kernel samples was significant $(P<0.05)$. After 90 days of maintenance, the conjugated diene value was increased significantly. When unsaturated fatty acids oxidized, displacement of double bonding occurred, so that the conjugated diene and triene were increased.

Anisidine value

By increasing storage time, the AV increased. In other words, in samples with $10 \%$ PPE coating, with an increase 


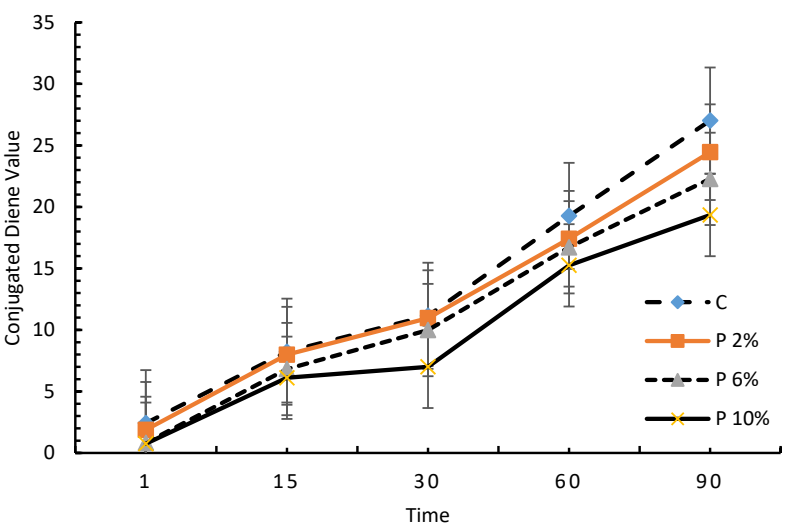

Figure 4. The effect of various concentrations of pomegranate peel extract coating on the changes in conjugated diene value during storage.

${ }^{*}$ C: Uncoated samples, P $2 \%$ : Specimen with $2 \%$ pomegranate peel extract coating, P 6\%: Specimen with 6\% pomegranate peel extract coating, and $P$ 10\%: Specimen with $10 \%$ pomegranate peel extract coating.

in storage time from 1 to 90 days, the AV increased from 0.75 to $19.34 \mathrm{mmol} / \mathrm{L}$. On the other hand, by increasing the PPE coating from 2 to $10 \%$ in 90 days, the number of the number of anisidine index decreased from 24.45 to $19.34 \mathrm{mmol} / \mathrm{L}$. The uncoated samples had the highest AV $(27.02 \mathrm{mmol} / \mathrm{L})$. According to the results, the effect of various concentrations of PPE on the changes of AV in treated samples was significant $(P<0.05)$. The effect of storage time on the amount of anisidine in walnut kernels was significant (Figure 5). The amount of anisidine increased significantly after 90 days of storage.

The effect of PPE coating on the fungal activity

At 90 days, by increasing the concentration of PPE from 2 to $10 \%$, the count of molds and yeasts dropped from 3.59 to $2.29 \mathrm{CFU} / \mathrm{g}$. The count of molds and yeasts in the uncoated sample was $5.81 \mathrm{CFU} / \mathrm{g}$. According to Figure 6, during the maintenance period, treatment group or coated samples the amount of mold and yeast in the control treatment is highest. There was a significant difference between the number of molds and yeasts in samples of PPE (coated) and control sample (uncoated) $(P<0.05)$. This indicates that the PPE reduced the growth rate of the fungus in the walnut kernels, so that by increasing the extract concentration, the mold and yeast growth rates decreased $(P<0.05)$.

\section{Discussion}

The phenolic compounds have good antioxidant properties and are often found in fruits and vegetables. As the results indicate, pomegranate has a range of phenolic compounds and antioxidant properties (34). Kim et al considered pomegranate as a rich source of antioxidants and phenolic substances (35). Other studies have shown that various parts of the pomegranate, such as peel and leaves, contain various phenolic substances (36). The antioxidant capacity

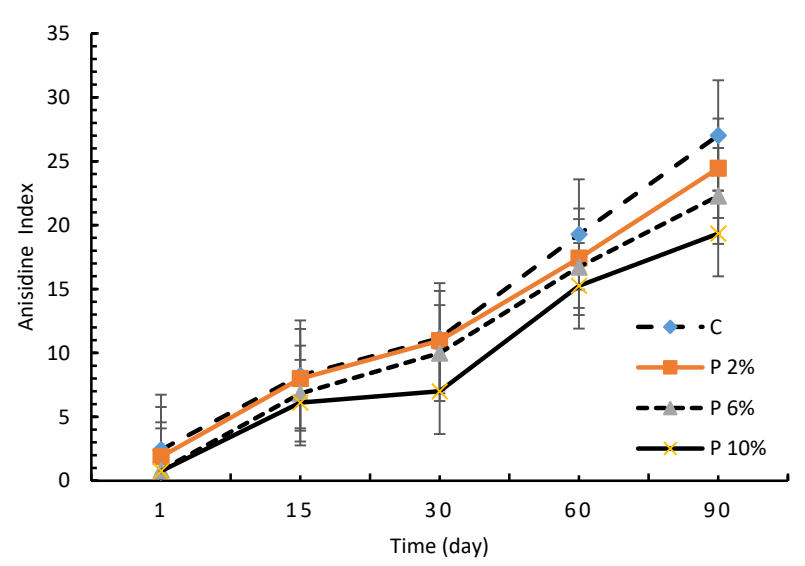

Figure 5. The effect of various concentrations of pomegranate peel extract coating on the changes in anisidine value during storage. ${ }^{*} \mathrm{C}$ : Uncoated samples, P 2\%: Specimen with $2 \%$ pomegranate peel extract coating, P 6\%: Specimen with 6\% pomegranate peel extract coating, and P 10\%: Specimen with 10\% pomegranate peel extract coating.

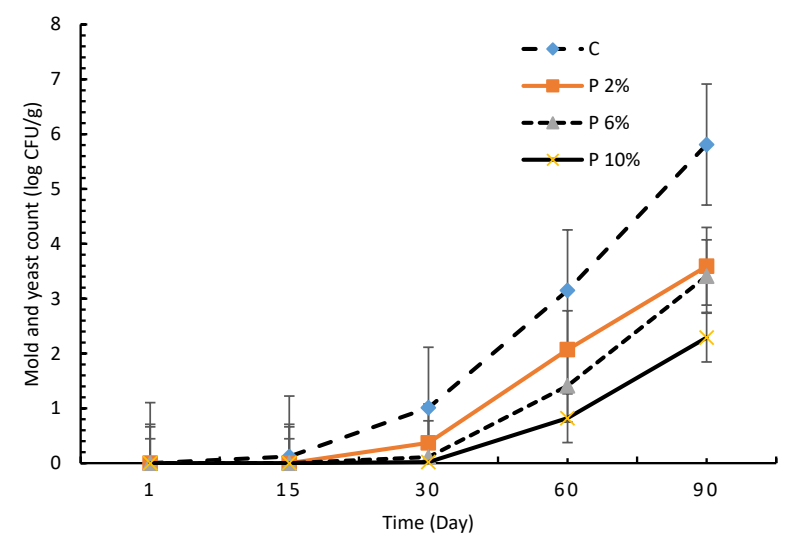

Figure 6. The effect of various concentrations of pomegranate peel extract on the changes in the count of mold and yeast in the walnut kernel during storage.

${ }^{*} \mathrm{C}$ : Uncoated samples, P $2 \%$ : Specimen with $2 \%$ pomegranate peel extract coating, P 6\%: Specimen with 6\% pomegranate peel extract coating, and P 10\%: Specimen with $10 \%$ pomegranate peel extract coating.

of the pomegranate peel due to its anthocyanins, including delphinidin, cyanidin, pelargonidin has been reported. Approximately, pomegranate peel contains $23 \%$ of all the anthocyanins present in pomegranate (37).

Percentage of free radical inhibition

Determination of DPPH free radicals' inhibition is one of the most reliable, accurate, easy, and affordable methods with high repeatability. It is used in vitro conditions to evaluate the antioxidant activity of herbal extracts (38). The results of this study showed that PPE had high levels of radical inhibition, but did not have the ability to synthesize BHA as an antioxidant. Berizi et al showed that PPE has a high ability to inhibit DPPH-free radicals. There was a significant difference between various concentrations of the extract in terms of antioxidant activity (39). The 
effect of alginate-based coatings boosted with PPE on the quality of Psidium guajava was investigated by Nair et al. Total phenolics and antioxidant activity were $8 \%$, and $9 \%$, respectively at the end of storage (40).

Walnut moisture content

The effect of various concentrations of PPE on the moisture changes of the treated samples was significant, so that by increasing the concentration of PPE, the moisture content of walnut samples also increased. This is due to the moisture absorption of the phenolic compounds by the PPE. The findings showed that the effect of storage time on the moisture content of walnut samples was significant $(P<0.05)$, and after 90 days of storage, the moisture content was significantly reduced. The results are consistent with the findings of Sarker et al, Akhtar et al, and Turgut et al, which showed that PPE maintains the moisture content of the product during storage (41-43).

\section{Acidity}

The different concentrations of PPE had a significant effect on the acidity changes of the treated samples $(P<0.05)$. Increasing acidity as a result of adding the extract, can be due to its saponin compounds. Waller reported that carboxyl groups contained in the sugary or aglycone part of saponin in the extract due to acidic properties, have the ability to increase the acidity of the food (44). RojasGrau et al showed that during storage, $\mathrm{pH}$ of the products decreased significantly (45). The results of the studies are similar to those of the present study.

\section{Peroxide value}

Peroxide is the primary product of the fatty substances oxidation. The presence of peroxide (as a catalyst) in oils or food products accelerates the oxidation. The effect of various concentrations of the extract on changes in PV was significant $(P<0.05)$. In general, the results showed that by increasing the concentration of the extract $(2 \%$ $10 \%)$, the stability of the product during storage was also increased. This increase in stability can be attributed to an increase in the concentration of phenolic and antioxidant compounds in the extract. The effect of tea leaf extracts on stability rapeseed oil under thermal conditions was investigated in the literature. The results showed that the acid index increased during the reaction, and the PV decreased by increasing the extract concentration (46). In another study, the effect of ethanolic and methanolic extracts of Pulicaria gnaphalodes on the oxidative stability of soybean oil was studied. Peroxide analysis showed that with increasing concentrations of the extracts from 200 to $800 \mathrm{ppm}$, the production of peroxide reduced (47). Kamkar et al evaluated the effect of natural antioxidants on the stability of canola oil. Evaluation of the PV of treated oil showed that the PV was decreased by increasing the extract concentration from 100 to $1000 \mathrm{ppm}$ (48). The results of the aforementioned studies are consistent with the results of this study. The using of fungal chitosan and PPE, in coating films for Oreochromis niloticus, and their microbiological, chemical and sensorial quality in storage at $4^{\circ} \mathrm{C}$, was investigated by Alsaggaf et al. The results showed coating could delay the spoilage parameters during storage time (49).

\section{Conjugated diene value}

After 90 days of maintenance, the conjugated diene value was significantly increased. When unsaturated fatty acids oxidized, displacements of double bonding occurred, so that the conjugated diene and triene were increased. The conjugated diene had a direct relation with the degree of oxidation. Investigation of the effect of thyme extract on the stability of corn oil showed that the heating time of the conjugated diene and triene compounds increased linearly, but this trend was significantly lower than that of the nonantioxidant oil (50). In another study, the effect of tea leaf extract on rapeseed oil was investigated and it was found that with increasing the extract concentration from $0.22 \%$ to $0.25 \%$, the amount of diene compounds decreased (51). The results of the above-mentioned studies are consistent with the findings of the present study.

\section{Anisidine value}

The increase of the anisidine index reflects the spontaneous oxidation reaction and the increase of secondary products resulting from the decomposition of hydroxides and carbonyl compounds with increasing time. In the present study, the amount of anisidine significantly increased after 90 days of storage. Mazaheri Kalhoroodi et al investigated the antioxidant effect of fennel seed extract on soybean oil stability compared to synthetic anti-oxidants BHA and BHT. The results showed that with increasing the concentration of the extract from 80 to $100 \mathrm{ppm}$, the anisidine index decreased significantly (52).

\section{The effect of PPE coating on the fungal activity}

According to Figure 6, during the maintenance period, the control treatment had the highest amount of mold and yeast. There was a significant difference between the number of mold and yeast in the coated samples with PPE extract and control sample (uncoated) $(\mathrm{P}<0.05$ This indicates that the PPE reduced the growth rate of the fungus in the walnut so that with the increase in the concentration of PPE, the mold and yeast growth rates decreased $(P<0.05)$. Antimicrobial activity of PPE may be due to the wide range of antibiotic compounds, among which phenols and tannins have been identified as the most important active ingredients in this field. Phenolic substances, together with high molecular weight proteins, form complex compounds and thus, after absorption, can react with cell enzymes (oxidase and reductase) present in the cytoplasm and cell wall. On the other hand, these materials can prevent the access of microorganisms to cell surface receptors. Ibrahium stated that Punicalagin forms 
a large part of the antioxidant compounds of PPE and most of the antimicrobial activity of PPE (14). The tannins and ellagitannins in pomegranate phenolic acids have antibacterial and antifungal activity. These phenolic compounds break down the cell wall, perforate the cytoplasmic membrane and decay the proteins, as a result, the function of membrane enzymes is interrupted and causes cell death. The above-mentioned results are similar to the results of this research. An abrupt increase in the growth of mold and yeast began on the 30th day. This suggests that in the early stages of preserving the walnut kernel, microorganisms were observed in a delayed phase, with a slight growth, but gradually entering the logarithmic phase and the growth of mold and yeast increased in walnut samples $(P<0.05)$, which can be attributed to the reduction of their polyphenolic content. Most phenolic compounds are in the form of bonding with other compounds, such as proteins, and only a small fraction of phenolic compounds are free (53). Therefore, it can be stated that their antimicrobial and antifungal properties are limited. The results of this study are consistent with the results of a study by Kazemizadeh and Fadaei Noghani on increasing the growth of mold and yeast by increasing the maintenance time (54). Antifungal activity of PPE for fusarium wilt of tomato was investigated by Rongai et al. The results showed that an increase in the concentration of extract led to a progressive decline in germination (55).

\section{Conclusion}

Due to environmental hazards caused by the use of synthetic and non-degradable films, many researchers have started to produce natural edible coatings for the preservation of foodstuffs, such as fruits and vegetables. The effect of PPE coating on the fungal activity, the quality and shelf life of walnut in 90 days of storage of walnut kernel was investigated. The results of this study showed that by increasing the percentage of PPE, mold and yeast growth decreased. The results suggest that P 10\% (samples containing $10 \%$ PPE) has effectively antifungal activity in the walnut, and it can be used in packaging industry to conserve walnut kernel quality. By increasing the extract concentration from $2 \%$ to $10 \%$, the walnut kernel stability increased during storage. So that the moisture content and acidity increased, but stability indices such as peroxide, anisidine, and conjugated diene values were significantly decreased. Therefore, the PPE can be used as a coating matter for walnut kernel stability as well as a natural preservative in walnut oil.

\section{Acknowledgments}

The authors wish to thank Department of Food Science and Technology, Yasooj Branch, Islamic Azad University, Yasooj, Iran, for the financial support.

\section{Ethical issue}

It is confirmed that this manuscript is the original work of the authors. It has not been published, nor is it under review in another journal, and it is not being submitted for publication elsewhere.

\section{Competing interests}

The authors declare that they have no conflict of interests.

\section{Authors' contributions}

All authors contributed equally and were involved in the study design, data collection, analysis, and interpretation. All authors critically reviewed, refined, and approved the manuscript.

\section{References}

1. Noorimotlagh Z, Mansourian M, Nourmoradi H, Shafieian Z, Banavi P. Study of knowledge and attitude of among Ilam University of Medical Sciences students regarding to food sanitation and safety. Journal of Ilam University of Medical Sciences 2015; 23(3): 8-15. [In Persian].

2. Shokri R, Hashemi M, Jorvand R, Hajiveisi H, Shamsi A, Golestanifar $\mathrm{H}$, et al. A survey on the knowledge and attitudes of Dehloran health network personnel about food safety and health. Journal of Advances in Environmental Health Research 2018; 6(1): 27-33. doi: 10.22102/ jaehr.2018.108388.1056.

3. Mexis SF, Badeka AV, Riganakos KA, Karakostas KX, Kontominas MG. Effect of packaging and storage conditions on quality of shelled walnuts. Food Control 2009; 20(8): 743-51. doi: 10.1016/j.foodcont.2008.09.022.

4. Salcedo CL, Lopez de Mishima BA, Nazareno MA. Walnuts and almonds as model systems of foods constituted by oxidisable, pro-oxidant and antioxidant factors. Food Res Int 2010; 43(4): 1187-97. doi: 10.1016/j.foodres.2010.02.016.

5. Buranasompob A, Tang J, Powers JR, Reyes J, Clark S, Swanson BG. Lipoxygenase activity in walnuts and almonds. LWT - Food Sci Technol 2007; 40(5): 893-9. doi: 10.1016/j.lwt.2006.05.003.

6. Bonilla LF, Tsuda K, Pulido N, Regnier J, Laurendeau A. Nonlinear site response evidence of K-NET and KiKnet records from the 2011 off the Pacific coast of Tohoku Earthquake. Earth planets space 2011; 63(7): 785-9. doi: 10.5047/eps.2011.06.012.

7. Beverly RL, Janes ME, Prinyawiwatkul W, No HK. Edible chitosan films on ready-to-eat roast beef for the control of Listeria monocytogenes. Food Microbiol 2008; 25(3): 5347. doi: $10.1016 / \mathrm{j} . \mathrm{fm} .2007 .11 .002$.

8. Rojas-Grau MA, Avena-Bustillos RJ, Olsen C, Friedman M, Henika PR, Martín-Belloso O, et al. Effects of plant essential oils and oil compounds on mechanical, barrier and antimicrobial properties of alginate - apple puree edible films. J Food Eng 2007; 81(3): 634-41.

9. Li Y, Guo C, Yang J, Wei J, Xu J, Cheng S. Evaluation of antioxidant properties of pomegranate peel extract in comparison with pomegranate pulp extract. Food Chem 2006; 96(2): 254-60. doi: 10.1016/j.foodchem.2005.02.033.

10. Braga LC, Shupp JW, Cummings C, Jett M, Takahashi JA, Carmo LS, et al. Pomegranate extract inhibits Staphylococcus aureus growth and subsequent enterotoxin production. J Ethnopharmacol 2005; 96(1-2): 335-9. doi: 10.1016/j.jep.2004.08.034. 
11. Burapadaja S, Bunchoo A. Antimicrobial activity of tannins from Terminalia citrina. Planta Med 1995; 61(4): 365-6. doi: 10.1055/s-2006-958103.

12. Heber D, Schulman RN, Seeram NP. Pomegranates: Ancient Roots to Modern Medicine. Boca Raton, USA: CRC Press; 2006.

13. Khan JA, Hanee S. Antibacterial properties of Punica granatum peels. Int J Appl Biol Pharm Technol 2011; 2(3): 23-7.

14. Ibrahium MI. Efficiency of pomegranate peel extract as antimicrobial, antioxidant and protective agents. World Journal of Agricultural Sciences 2010; 6(4): 338-44.

15. Ullah N, Ali J, Khan FA, Khurram M, Hussain A, Rahman I, et al. Proximate composition, minerals content, antibacterial and antifungal activity evaluation of pomegranate (Punica granatum L.) peels powder. Middle East Journal of Scientific Research 2012; 11(3): 396-401.

16. Noda M, Wataha JC, Kaga M, Lockwood PE, Volkmann KR, Sano H. Components of dentinal adhesives modulate heat shock protein 72 expression in heat-stressed THP-1 human monocytes at sublethal concentrations. J Dent Res 2002; 81(4): 265-9. doi: 10.1177/154405910208100408.

17. Devatkal SK, Naveena BM. Effect of salt, kinnow and pomegranate fruit by-product powders on color and oxidative stability of raw ground goat meat during refrigerated storage. Meat Sci 2010; 85(2): 306-11. doi: 10.1016/j.meatsci.2010.01.019.

18. Qu P, Gao Y, Wu G, Zhang L. Nanocomposites of poly (lactic acid) reinforced with cellulose nanofibrils. BioResources 2010; 5(3): 1811-23.

19. Labib Ahmed Hossin F. Effect of pomegranate (Punica granatum) peels and it's extract on obese hypercholesterolemic rats. Pakistan Journal of Nutrition 2009; 1251-7.

20. Poyrazoglu E, Gokmen V, Artık N. Organic acids and phenolic compounds in pomegranates (Punica granatum L.) grown in Turkey. J Food Compost Anal 2002; 15(5): 567-75. doi: $10.1006 /$ jfca.2002.1071

21. Machado LF, Andrade AB, Hostim-Silva M, Barreiros JP. Habitat use by the juvenile dusky grouper Epinephelus marginatus and its relative abundance, in Santa Catarina, Brazil. Aqua: Journal of Ichthyology and Aquatic Biology 2003; 6(4): 133-8.

22. Yazdanpanah S, Arjmand P, Pourarang H, Mohammadi Jafari M. Investigation of heat stablity of pomegranate peel extract. Journal of Science and Technology of Agriculture and Natural Resources 2009; 13(47):95-102. [In Persian].

23. Selahvarzi Y, Tehranifar A, Jahanbakhsh Mashhadi V. The mechanism of control of post-harvest fungi by extract of different parts of pomegranate. The First National Sustainable Agriculture Conference and Healthy Crop Production; 2010 Nov 10-11; Isfahan Agricultural and Natural Resources Research Center, Isfahan; 2010. [In Persian].

24. Parniakov O, Lebovka NI, Van Hecke E, Vorobiev E. Pulsed electric field assisted pressure extraction and solvent extraction from Mushroom (Agaricus bisporus). Food Bioproc Tech 2014; 7(1): 174-83. doi: 10.1007/s11947-0131059-y.

25. Ribeiro SO, Nogueira LS, Gago S, Almeida PL, Corvo MC, de Castro B, et al. Desulfurization process conciliating heterogeneous oxidation and liquid extraction: organic solvent or centrifugation/water? Appl Catal A Gen 2017; 542: 359-67. doi: 10.1016/j.apcata.2017.05.032.

26. Ziyaadini M, Zahedi MM, Khosravinia S. Ultrasoundassisted extraction combined with reverse phase-dispersive liquid-liquid micro extraction as a new approach for preconcentration and spectrophotometric determination of total phenol in marine sediments of Chabahar Bay. Mar Pollut Bull 2016; 109(1): 104-9. doi: 10.1016/j. marpolbul.2016.06.013.

27. Burits M, Bucar F. Antioxidant activity of Nigella sativa essential oil. Phytother Res 2000; 14(5): 3238. doi: 10.1002/1099-1573(200008)14:5<323::AIDPTR621>3.0.CO;2-Q.

28. Hosseini H, Ghorbani M, Sadeghi Mahoonak AR, Maghsoudlou Y. Application of conjugated diene value as a measure of walnut oxidation progress. Electronic Journal of Food Processing and Preservation 2012; 4(1): 1-13. [In Persian].

29. American Association of Cereal Chemists (AACC). Approved Methods of the AACC. [cited 2018 Sep 20] Available from: http://methods.aaccnet.org/summaries/44-15-02.aspx.

30. AOAC International, Latimer GW. Official Method of Analysis of AOAC International. 19th ed. AOAC International; 2012.

31. Mehta BM, Darji VB, Aparnathi KD. Comparison of five analytical methods for the determination of peroxide value in oxidized ghee. Food Chem 2015; 185: 449-53. doi: 10.1016/j.foodchem.2015.04.023.

32. Fathi A, Sahari MA, Barzegar M, Naghdi Badi H. Antioxidant activity of Satureja hortensis L. essential oil and its application in safflower oil. Journal of Medicinal Plants 2013; 12(45): 51-67.

33. American Oil Chemists' Society (AOCS). Official Methods and Recommended Practices of the AOCS. Urbana, Illinois, USA: AOCS; 1998.

34. Heim KE, Tagliaferro AR, Bobilya DJ. Flavonoid antioxidants: chemistry, metabolism and structure-activity relationships. J Nutr Biochem 2002; 13(10): 572-84. doi: 10.1016/S0955-2863(02)00208-5.

35. Kim ND, Mehta R, Yu W, Neeman I, Livney T, Amichay A, et al. Chemopreventive and adjuvant therapeutic potential of pomegranate (Punica granatum) for human breast cancer. Breast Cancer Res Treat 2002; 71(3): 203-17.

36. Heber D, Schulman RN, Seeram NP. Pomegranates: Ancient Roots to Modern Medicine. US: CRC Press, Taylor \& Francis Group; 2006.

37. Sarkhosh A, Zamani Z, Fatahi R, Ghorbani H, Hadian J. A review on medicinal characteristics of pomegranate (Punica granatum L.). Journal of Medicinal Plants 2007; 2(22):13-24. [In Persian].

38. Singh S, Singh RP. In vitro methods of assay of antioxidants: an overview. Food Rev Int 2008; 24(4): 392-415. doi: $10.1080 / 87559120802304269$.

39. Berizi E, Shekarforoush S, Hosseinzadeh S. Investigation of the antioxidant properties of metanolic peel extract of pomegranate (Punica granatum var. Rabbab). Journal of Food Hygiene 2016; 6(23): 13-21. [In Persian].

40. Nair MS, Saxena A, Kaur C. Effect of chitosan and alginate based coatings enriched with pomegranate peel extract to extend the postharvest quality of guava (Psidium 
guajava L.). Food Chem 2018; 240: 245-52. doi: 10.1016/j. foodchem.2017.07.122.

41. Sarker MS, Yim KJ, Ko SY, Uuganbayar D, Kim GM, Bae $\mathrm{IH}$, et al. Green tea level on growth performance and meat quality in finishing pigs. Pakistan Journal of Nutrition 2010; 9(1): 10-4. doi: 10.3923/pjn.2010.10.14.

42. Akhtar S, Ismail T, Fraternale D, Sestili P. Pomegranate peel and peel extracts: chemistry and food features. Food Chem 2015; 174: 417-25. doi: 10.1016/j.foodchem.2014.11.035.

43. Turgut SS, Isikci F, Soyer A. Antioxidant activity of pomegranate peel extract on lipid and protein oxidation in beef meatballs during frozen storage. Meat Sci 2017; 129: 111-9. doi: 10.1016/j.meatsci.2017.02.019.

44. Waller GR. Saponins: chemistry and pharmacology of natural products. J Am Chem Soc 1996; 118(35):8509.

45. Rojas-Grau MA, Tapia MS, Rodriguez FJ, Carmona AJ, Martin-Belloso O. Alginate and gellan-based edible coatings as carriers of antibrowning agents applied on fresh-cut Fuji apples. Food Hydrocoll 2007; 21(1): 118-27. doi: 10.1016/j. foodhyd.2006.03.001.

46. Zhang D, Hamauzu Y. Phenolic compounds and their antioxidant properties in different tissues of carrots (Daucus carota L.). J Food Agric Environ 2004; 2(1): 95-100.

47. Zandi P, Gordon MH. Antioxidant activity of extracts from old tea leaves. Food Chem 1999; 64(3): 285-8. doi: 10.1016/ S0308-8146(98)00047-8.

48. Kamkar A, Ardekani MRS, Shariatifar N, Misagi A, Nejad ASM, Jamshidi AH. Antioxidative effect of Iranian Pulicaria gnaphalodes L. extracts in soybean oil. S Afr J Bot 2013; 85: 39-43. doi: 10.1016/j.sajb.2012.12.001.

49. Alsaggaf MS, Moussa SH, Tayel AA. Application of fungal chitosan incorporated with pomegranate peel extract as edible coating for microbiological, chemical and sensorial quality enhancement of Nile tilapia fillets. Int J Biol Macromol 2017; 99: 499-505. doi: 10.1016/j. ijbiomac.2017.03.017.

50. Shahidi F, Wanasundara U. Effect of natural antioxidants on the stability of canola oil. Developments in Food Science 1995; 37: 469-79.

51. Karoui IJ, Dhifi W, Jemia MB, Marzouk B. Thermal stability of corn oil flavoured with Thymus capitatus under heating and deep-frying conditions. J Sci Food Agric 2011; 91(5): 927-33. doi: 10.1002/jsfa.4267.

52. Mazaheri Kalahrodi M, Bassiri AR, Jalali H. Evaluation of antioxidant properties of essential oil of fennel (foeniculum vulgare) and its effect on the oxidative stability of soybean oil. Iranian Journal of Biosystems Engineering 2015; 45(2):131-139. [In Persian].

53. Bind A, Singh SK, Prakash V, Kumar M. Evaluation of antioxidants through solid state fermentation from pomegranate peels using Aspergillus niger and it's Antibacterial properties. Int J Pharm Biol Sci 2014; 4(1): 104-12.

54. Kazemizadeh R, Fadaei Noghani V. The determination of antioxidant activity, total polyphenols and microbial total count of functional flavored milk containing pomegranate peel extract and date datesyrup during cold storage. Iranian Food Science and Technology Research Journal 2016, 12(4): 489-98. [In Persian].

55. Rongai D, Pulcini P, Pesce B, Milano F. Antifungal activity of pomegranate peel extract against fusarium wilt of tomato. Eur J Plant Pathol 2017; 147(1): 229-38. doi: 10.1007/ s10658-016-0994-7. 